\title{
Discussion on Cost management in Project Bidding
}

\author{
CUI BaoXia \\ Architectural and Civil Engineering Institute, Inner Mongolia Scientific and Technical University, \\ Baotou Inner Mongolia 014010, china \\ cuibaoxiadd@163.com
}

Keywords: bidding, cost control, project

Abstract. Bidding is a major event that affects the construction companies' survival. This article will propose recommendations on the purpose and principles of bidding, the cost control, and how to improve the input-output ratio of the bidding process.

\section{Introduction}

With the further development of the socialist market economy, the project bidding has been widely used. How to do the bidding well and try to control costs, improve the input-output ratio of the bidding process, and achieved high economic efficiency, are the issues that construction enterprises must face. This article will propose recommendations on the purpose and principles of bidding, the cost control, and how to improve the input-output ratio of the bidding process as follows:

\section{The purpose and principles of project bidding}

The purpose of the project bidding is to win the bidding with the highest possibility and obtain the right to project construction. But sometimes the bidding is blind, which is kind of inevitable. Aimlessly attending the bidding wherever there is one. Therefore, to do a good bidding job, we must have a clear purpose and the bidding principles, in order to improve the input-output ratio of the bidding process, and achieved good results. Bidding principles.

\section{Select the project to bid}

(1) The feasibility and possibility of the project shall be considered. First, the enterprise must consider its own situation and shall be able to ensure a balanced and continuous construction of the projects, not winning the most possible bidding of projects. Secondly, with the successful bidding, the enterprise shall be able to give full play to its characteristics, expertise, and the technological and equipment advantages, and be able to avoid its weaknesses. Thirdly, it is better to consider whether the bidding offer is destined to win based on the technical \& economic information and the bidding offer prices of market competitors. Without considering the above, it is not wise to bid, not to mention accompanying other enterprise's bidding

(2) The reliability of the project shall be considered. First, the enterprise shall fully understand whether the construction project has been formally approved, and if the funding sources are reliable, if the owner's preparatory work is in place and if the main material and equipment supply is finalized. Preferred conditions of the project are: (1) one of the key projects (highly likely funds will be in place ); (2) have experience in such construction projects; (3) local projects; (4) projects using universal construction machinery and equipment; (5) projects with sound project 
management regulations; (6) projects with land acquisition, displacement \& resettlement accomplished; (7) projects with highly qualified owners \& supervision teams; 8projects with normal FIDIC terms; (9) projects that has good relationship with the local government; (10) projects that matches the main business scope \& scale of the enterprise.

On the contrary, the enterprise shall consider aborting those projects that are from outside the province, with low funds-in-place rate, that requires a lot of upfront payment, far away from the enterprise's headquarter, with uneven and not high earnings, and the highly risky projects and those projects with irrational construction structures.

(3) According to estimation of profits, the bidding projects shall be classified as A, B, C categories for management purpose. Class A category is the key target, Class B category are the general targets and Class $\mathrm{C}$ category are the targets to be selected and followed. Dynamic management shall be applied to A, B, C category targets based on the change of situation, and should not remain unchanged. Blind bidding \& reluctant bidding shall be avoided since they will cause a great waste of financial, human and material resources.

\section{To determine different bidding strategies and tactics for different projects.}

To determine the bidding strategies and tactics for different projects according to the feasibility, reliability and likelihood analysis of each bidding project in combination with the enterprise's own situation.

\section{Control of the bidding cost}

The enterprise shall have a plan on bidding and spending. We can not say yes to unplanned spending just because the bidding is very important, since it will result in an invisible waste of manpower and financial resources. Therefore, the following several jobs shall be carried out to control the bidding costs.

\section{Formulation of expense standards for bidding activity.}

The main goal is to formulate expense standards for the travel, food, lodging, transportation, and client entertainment etc. The principles of expenditure standard formulation shall be to not only satisfy the ongoing normal bidding activities, but also be frugal and to make every penny of spending play a role. According to recent years' of bidding activities, it is recommended that the enterprise shall refer to the standard for travel reimbursement, and develop its own expenditure standards for individual's accommodation, automobile, ship \& air travel, food subsidies and other items of expenditure to entertain the bidding process and may carry out a lump sum on part of personnel costs.

\section{Proper control of the bidding office expenses.}

Bidding office expenses include the preparation of bidding documents, the daily office costs such as printing and photocopying. Bidding documents shall be prepared on a computer of the business department, and the printing and photocopying shall be minimized during documents preparation; Try not to print or photocopy in a public print \& copy shop. Because it will not only increase the bidding expenses, but also cause leakage of confidential bidding information, causing undue losses to the bidding of the enterprise. 


\section{Management of the financial \& notary fees during the bidding process.}

During the bidding process, the owners will often require companies to submit all types of bank guarantees, and require notary departments to notarize the bidders, the entrusted agent, the authorized person or the bidding documents. In this aspect, the enterprises may try to reduce the commission fee of the bank according to the specified range of the local account opening bank, and sign a cooperation agreement with the notary department to reduce the notary expenses.

\section{Try to use the high-tech means of information networks.}

The companies should continue the use of modern high-tech means if they want to progress, and so is the bidding. For example, online information \& network queries shall be used as much as possible, so far as the acquirement \& following-up of some project bidding information is concerned. Contacting by means of telephone or telecommunications will replace the need to send someone to travel by plane or train. This can save a lot of travel \& accommodation expenses.

\section{Notes to the bidding}

Bidding is a complex task, involving overall qualities of the bidders, bid decision, modernization of bidding appliances, as well as bidding expenses guarantees etc. To be specific, attention needs to be paid on the following aspects:

\section{Establish a good mechanism.}

Carry out training and improve the overall qualities of the bidding personnel. The level of the overall qualities of bidding staff is an important factor affecting the quality of bidding documents preparation. Therefore, training personnel and improving the overall qualities of the bidding should be regarded as a long-term task. The combined inner \& outside training will make a number of bidding businessmen with high policy concepts, thorough knowledge of bidding theories, and with more practical experience in the bidding business, and they will exercise and improve their overall qualities in practice. Enterprises should establish a good incentive mechanism: many forms of spiritual \& material rewards such as public praise, publicized awards etc. shall be given to individuals with outstanding achievements in the bidding, in recognition of their meritorious services and fully mobilize the enthusiasm of the bidding personnel.

\section{To be equipped with modern bidding facilities.}

Now the bidding requirements are getting increasingly demanding, and bidding preparation time is short. Therefore, the bidding staff must be equipped with modern bidding software and hardware facilities, such as desktop and laptop computers (should be able to access the internet), scanners, printers, copiers, fax machines, and bidding software etc., so that enterprises can capture market information in a timely, accurate, multi-channel manner and thus lay a good foundation for being advantageous and achieving higher economic efficiency.

\section{To ensure reasonable expenses incurred by bidding.}

Bidding cost money, and enterprises must guarantee the reasonable expenses of the important bidding projects, properly ensure the expenses of the general bidding projects, and make decisions 
based on the actual situations for the to-be-selected and followed-up projects.

In short, bidding is a major event that affects the construction companies' survival. Enough attention and support shall be given to all aspects of bidding related work. Efforts shall be made to improve the input-output ratio of bidding process in order to ensure the enterprise to survive and prosper in the socialist market economy.

\section{References}

[1] Kui Du. Research on comparison the Bill of quantities quotation price and traditional quotation mode [J]. Building economy2013,(1).

[2] Specification construction engineering the quantities bill valuation.(GB50500-2013) [S].China building industry press(2013).

[3] Yilin Yin. In terms of project cost and control [M]. China planning press(2005).

[4] Zhifeng Qiu. Construction enterprise cost management research [J]. Shanxi building 2006,(32).

[5] Shaocong Ma.. To adapt to the evaluation of the lowest bid price method of bidding skills [J]. Shanxi building 2006,(32). 